\title{
Acute traumatic abdominal wall hernia
}

\author{
D. den Hartog • W. E. Tuinebreijer • \\ P. P. Oprel · P. Patka
}

Received: 21 January 2010 / Accepted: 16 April 2010 / Published online: 4 May 2010

(C) The Author(s) 2010. This article is published with open access at Springerlink.com

\begin{abstract}
Although blunt abdominal trauma is frequent, traumatic abdominal wall hernias (TAWH) are rare. We describe a large TAWH with associated intra-abdominal lesions that were caused by high-energy trauma. The diagnosis was missed by clinical examination but was subsequently revealed by a computed tomography (CT) scan. Repair consisted of an open anatomical reconstruction of the abdominal wall layers with reinforcement by an intraperitoneal composite mesh. The patient recovered well and the results of a post-operative CT scan are presented.
\end{abstract}

Keywords Blunt trauma Primary closure $\cdot$ Abdominal hernia $\cdot$ Mesh prosthesis $\cdot$ Abdominal wall disruption

\section{Introduction}

Blunt trauma of the abdominal wall can lead to a traumatic abdominal wall hernia (TAWH). Damschen et al. [1] defined TAWH as the "herniation through disrupted musculature and fascia associated with adequate trauma, without skin penetration, and no evidence of a prior hernia defect at the site of injury". Although this type of hernia is unusual, it has been described in some reviews [2-7]. Two reviews

D. den Hartog $(\bowtie)$ · P. P. Oprel · P. Patka

Department of Surgery and Traumatology,

Erasmus MC, University Medical Center Rotterdam,

Office H-960, P.O. Box 2040, 3000 CA Rotterdam,

The Netherlands

e-mail: d.denhartog@erasmusmc.nl

W. E. Tuinebreijer

Relweg 59, 1949 EC Wijk aan Zee,

The Netherlands studied TAWH, especially in the lumbar position [8, 9]. The increased abdominal pressure and shearing forces likely cause disruption of the abdominal wall muscles and fasciae. Although the skin can be bruised, it normally remains intact [10]. We describe the history and imaging of a patient with a traumatic abdominal wall hernia and the operative treatment.

\section{Case report}

A 59-year-old male sustained a fall from a height of $9 \mathrm{~m}$ onto a pile of steel bars, landing on his right flank. Upon arrival of helicopter emergency medical services, the patient was alert and complained of pain in the abdomen. An Advanced Trauma Life Support (ATLS) survey revealed a right-sided pneumothorax, which was treated with a chest tube. After this intervention, the patient was respiratorily and haemodynamically stable and transported to the emergency department. Upon arrival, the initial assessment according to the ATLS protocol was performed without any new findings according to the $\mathrm{A}, \mathrm{B}, \mathrm{C}$ and $\mathrm{D}$ approaches. During the secondary survey, the effects of the blunt abdominal trauma were observed. Inspection revealed a large swelling at the right side of the abdomen, with abrasions of the overlying skin (Fig. 1). Palpation of the right abdominal wall was extremely painful. Focussed assessment with sonography for trauma identified the presence of free intraperitoneal fluid around the spleen. An orbital fracture with eyelid laceration was also diagnosed.

In addition, a computed tomography (CT) scan of the abdomen showed a traumatic hernia of the right lateral abdomen, with protrusion of bowel and laceration of the spleen (Fig. 2). The patient was transported to the operating theatre, and exploration of the abdomen through a median 


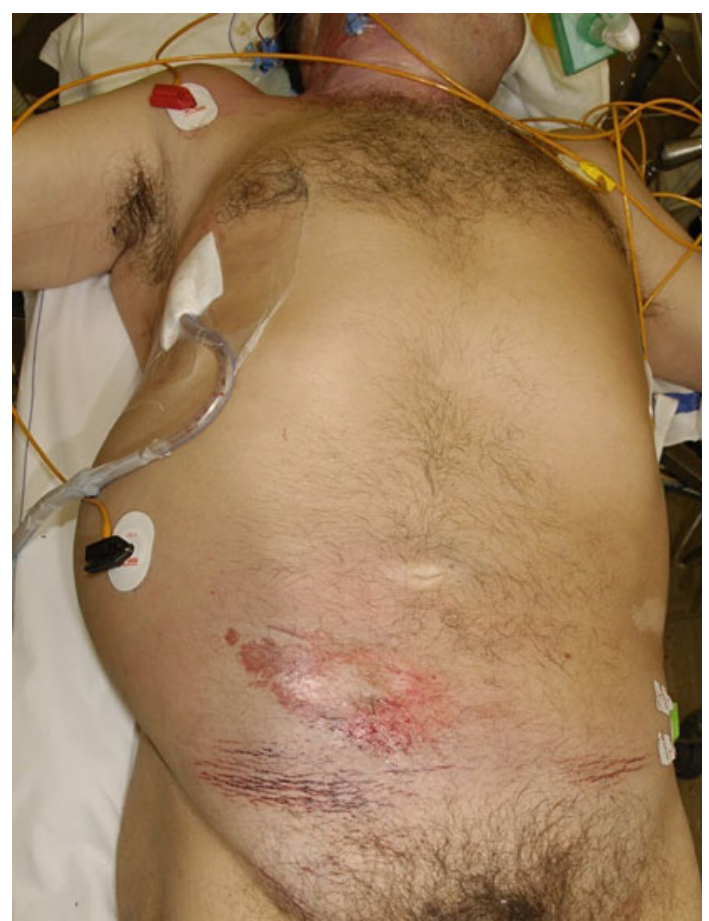

Fig. 1 Patient after blunt abdominal trauma with swelling of the right hemi-abdomen

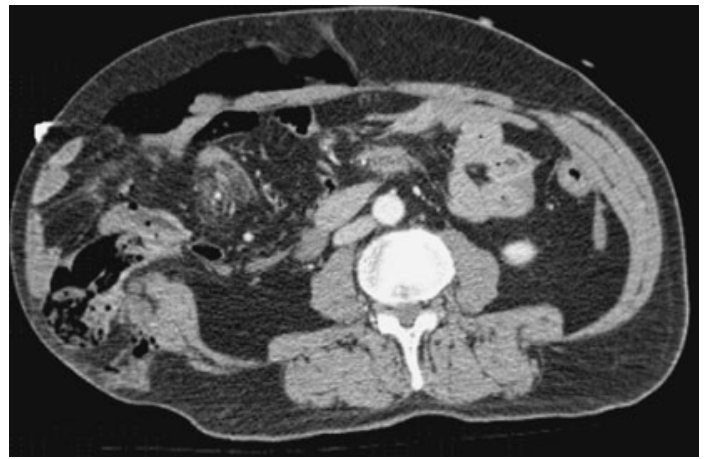

Fig. 2 Preoperative abdominal computed tomography (CT) scan demonstrating three ruptured muscle layers on the right side

incision revealed a transverse rupture of the total abdominal wall, including rectus muscle and external, transverse and internal abdominal muscles, with a length of $30 \mathrm{~cm}$ from the midline to the vertebral column on the right side (Fig. 3). The small bowel, ascending colon and the right lobe of the liver were herniated due to this defect. A nonvital part of the small bowel $(10 \mathrm{~cm})$ was resected, and haemorrhages from the mesentery and spleen were treated. The skin and subcutaneous tissue of the lower lateral abdomen showed deglovement. The ruptured layers of the abdominal wall were sutured separately. This anatomical reconstruction was reinforced with an intra-abdominal polyester composite mesh $\left(\right.$ Parietex $^{\circledR}$ ) with at least $4 \mathrm{~cm}$ overlap and fixed with sutures and taggers. After closure of

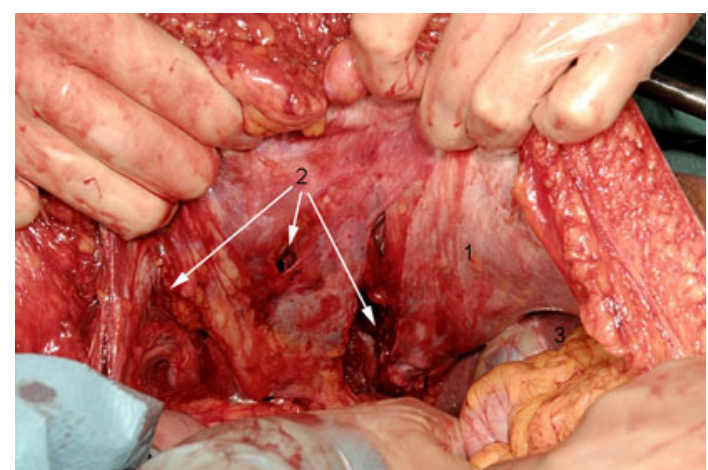

Fig. 3 Intra-operative picture of the right inner abdominal wall with rupture of all muscle layers. Head of patient at right side of the picture. 1 Parietal peritoneum, 2 rupture of abdominal muscle layers, 3 liver

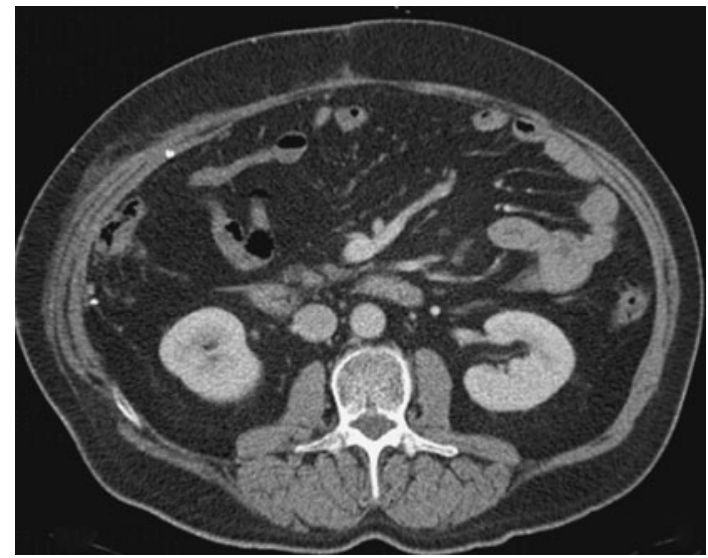

Fig. 4 Post-operative abdominal CT scan demonstrating anatomical restoration of the right abdominal wall with the use of an intra-abdominal mesh fixated with taggers

the linea alba, the overstretched median fascia below the umbilicus was protected by an absorbable polyglactin mesh $\left(\right.$ Vicryl $\left.^{\circledR}\right)$. Post-operatively, the patient developed superficial skin necrosis in the area of the abdominal wall with deglovement, which healed by secondary intention assisted by a vacuum assisted closure system. A CT scan of the abdomen 4 months after the operation showed the anatomical reconstruction of the right abdominal wall with the use of an intra-abdominal mesh fixed with taggers (Fig. 4). Physical examination in the outpatient department showed no recurrence after 1 year.

\section{Discussion}

Our patient sustained a high-energy trauma caused by a fall from a large height. This trauma gave rise to the TAWH and associated devascularisation of the small bowel, necessitating bowel resection. Low energy trauma can lead to smaller TAWHs, which can easily be missed on physical 
evaluation. Handlebar injury is an example of a low energy trauma that can lead to TAWH $[2,11,12]$. This smaller TAWH can and often will be treated secondarily due to delayed diagnosis. The diagnosis of a TAWH on physical examination can be difficult; because of its rare occurrence, a diagnosis of TAWH is not often considered. With TAWHs, the elastic skin remains intact. In our patient, the TAWH was not diagnosed by physical examination, and the very tender right hemi-abdomen was thought to be associated with intra-abdominal lesions. Because life-threatening intra-abdominal injuries can occur after high-energy trauma, a CT scan should be used as a diagnostic method [13]. The CT scan in this case led to the diagnosis of TAWH after careful examination of the abdominal wall and also to multiple haematomas in the mesentery and a spleen laceration. The strong shear forces had split the three layers of the lateral abdominal wall and the peritoneum. With the routine use of CT scans after blunt trauma, TAWH will be accurately diagnosed more often. TAWH can be operated on by an incision overlying the defect, but in this case, a midline exploratory laparotomy was necessary for the associated intra-abdominal injuries. A late diagnosed TAWH has also been operated on laparoscopically [14]. In addition, because of the associated intra-abdominal injuries, delayed exploration of the TAWH was not a treatment option in our case [15]. We combined the primary closure in the anatomical layers with an intraperitoneal mesh because the fascia was stretched out by the trauma and the hernia was very large. We used a composite mesh because the inner side was in direct contact with the bowels. In a recent review of the open treatment of incisional hernia, the pooled infection rate for mesh use was $10.1 \%$ [16]. Also, in a recent retrospective study of 206 open sublay mesh repairs with intraperitoneal placement of a composite mesh, the infection rate was $10.2 \%$ in a 9.5 -year period [17]. In our case, resection of a small bowel section could have increased the risk of a mesh infection. The high infection rate has to be weighed against the risk of recurrence. In a series of eight acutely repaired TAWHs without mesh, three developed a recurrent hernia after 8 months [6]. In another series of seven acute repairs of TAWHs, the repair attempt was only successful in two patients [18]. Thus, the acute repair of a large TAWH should not be underestimated because of the associated injuries and the risk of a recurrence.

\section{References}

1. Damschen DD, Landercasper J, Cogbill TH, Stolee RT (1994) Acute traumatic abdominal hernia: case reports. J Trauma 36:273-276

2. Haimovici L, Papafragkou S, Kessler E, Angus G (2007) Handlebar hernia: traumatic abdominal wall hernia with multiple enterotomies. A case report and review of the literature. J Pediatr Surg 42:567-569

3. Belgers HJ, Hulsewe KW, Heeren PA, Hoofwijk AG (2005) Traumatic abdominal wall hernia: delayed presentation in two cases and a review of the literature. Hernia 9:388-391

4. Mahajna A, Ofer A, Krausz MM (2004) Traumatic abdominal hernia associated with large bowel strangulation: case report and review of the literature. Hernia 8:80-82

5. Ganchi PA, Orgill DP (1996) Autopenetrating hernia: a novel form of traumatic abdominal wall hernia - case report and review of the literature. J Trauma 41:1064-1066

6. Netto FA, Hamilton P, Rizoli SB, Nascimento B Jr, Brenneman FD, Tien $\mathrm{H}$ et al (2006) Traumatic abdominal wall hernia: epidemiology and clinical implications. J Trauma 61:1058-1061

7. Wood RJ, Ney AL, Bubrick MP (1988) Traumatic abdominal hernia: a case report and review of the literature. Am Surg 54:648-651

8. Burt BM, Afifi HY, Wantz GE, Barie PS (2004) Traumatic lumbar hernia: report of cases and comprehensive review of the literature. J Trauma 57:1361-1370

9. Esposito TJ, Fedorak I (1994) Traumatic lumbar hernia: case report and literature review. J Trauma 37:123-126

10. Brett D, Seybold D, Michalski S, Muhr G (2008) Acute traumatic abdominal wall hernia after blunt abdominal trauma. Unfallchirurg 111:361-364

11. Fraser N, Milligan S, Arthur RJ, Crabbe DC (2002) Handlebar hernia masquerading as an inguinal haematoma. Hernia 6:39-41

12. Mancel B, Aslam A (2003) Traumatic abdominal wall hernia: an unusual bicycle handlebar injury. Pediatr Surg Int 19:746-747

13. Deunk J, Brink M, Dekker HM, Kool DR, van Kuijk C, Blickman JG et al (2009) Routine versus selective computed tomography of the abdomen, pelvis, and lumbar spine in blunt trauma: a prospective evaluation. J Trauma 66:1108-1117

14. Vargo D, Schurr M, Harms B (1996) Laparoscopic repair of a traumatic ventral hernia. J Trauma 41:353-355

15. Sall I, El KH, Bouchentouf SM, Ait AA, Bounaim A, Hajjouji A et al (2009) Delayed repair for traumatic abdominal wall hernia: is it safe? Hernia 13:447-449

16. den Hartog D, Dur AHM, Tuinebreijer WE, Kreis RW (2008) Open surgical procedures for incisional hernias. Cochrane Database of Systematic Reviews 3, http://www2.cochrane.org/reviews/ en/ab006438.html

17. Cobb WS, Carbonell AM, Kalbaugh CL, Jones Y, Lokey JS (2009) Infection risk of open placement of intraperitoneal composite mesh. Am Surg 75:762-767

18. Brenneman FD, Boulanger BR, Antonyshyn O (1995) Surgical management of abdominal wall disruption after blunt trauma. J Trauma 39:539-544

Open Access This article is distributed under the terms of the Creative Commons Attribution Noncommercial License which permits any noncommercial use, distribution, and reproduction in any medium, provided the original author(s) and source are credited. 